Research Article

\title{
Determination of Parameters of the Discrete Element Bond Model for Asphalt Mixture Based on Splitting Test
}

\author{
Jingsong Shan $\mathbb{D}^{1},{ }^{1}$ Yang Du $\mathbb{D}^{1},{ }^{1}$ Dahai Fan, ${ }^{2}$ and Laiyao Guo ${ }^{3}{ }^{3}$ \\ ${ }^{1}$ Shandong Key Laboratory of Civil Engineering Disaster Prevention and Mitigation, \\ Shandong University of Science and Technology, Qingdao 266590, China \\ ${ }^{2}$ Qingdao Guan Tong Municipal Engineering Co., Ltd., Qingdao 266001, China \\ ${ }^{3}$ Jinan Urban Construction Group, Jinan 250031, China \\ Correspondence should be addressed to Jingsong Shan; cyhsjs@163.com
}

Received 26 January 2019; Revised 24 February 2019; Accepted 28 March 2019; Published 2 May 2019

Academic Editor: Xu Yang

Copyright (c) 2019 Jingsong Shan et al. This is an open access article distributed under the Creative Commons Attribution License, which permits unrestricted use, distribution, and reproduction in any medium, provided the original work is properly cited.

\begin{abstract}
A discrete element method (DEM) has widely been used to simulate asphalt mixture characteristics, and DEM models can consider the effect of aggregate gradation and interaction between particles. However, proper selection of model parameters is crucial to obtain convincing results from DEM-based simulations. This paper presents a method to appropriately determine the mechanical parameters to be used in DEM-based simulation of asphalt concrete mixture. Splitting test specimens are prepared by using asphalt mixture, and the splitting test results are compared with simulation results from two-dimensional (2D) DEM and three-dimensional (3D) DEM. Basing on the DEM results, the effects of contact model parameters on the simulation results are analyzed. The slope of the load-displacement curve at the beginning stage is mainly affected by the stiffness parameters, and the peak load is mainly determined by using the value of the bond strength. The laboratory splitting test of AC-20 and AC-13 specimens were performed at different temperatures, namely, $-10^{\circ} \mathrm{C}, 0^{\circ} \mathrm{C}, 10^{\circ} \mathrm{C}$, and $20^{\circ} \mathrm{C}$, and the load-displacement relationships were plotted. According to the real load-displacement curve's slope at the beginning stage and peak load applied, the range of DEM bond model parameters is determined. On the basis of DEM results of the splitting test, the relationships between simulation load-displacement curve's characteristics and bond model parameters are fitted. The values of the parameters of the DEM contact bond model at different temperatures are obtained depending on the actual load-displacement curve's initial slope and peak load. Lastly the DEM and laboratory test results are compared, which illustrates that the parallel bond model can well simulate the behavior of asphalt mixture.
\end{abstract}

\section{Introduction}

Asphalt mixture is a composite material comprised of graded aggregate, filler, asphalt, and air voids. With the variation in the proportion of the components, the particles in asphalt mixture may exhibit different spatial distribution after compaction [1]. Particularly, the asphalt mixture may have different mechanical properties because the mixture performance is closely associated with coarse aggregate skeleton and asphalt content. Currently, numerical methods used to simulate the mechanical properties of asphalt mixture are mainly based on continuum models, such as the finite element method (FEM). However, continuum models are unable to fully reflect the heterogeneity of asphalt mixture, such as aggregate gradation, sand mastic distribution, and air-void characteristics [2].

The discrete element method (DEM), proposed by American Cundul P.A in 1971, is mainly used to analyze the mechanical properties of the discontinuity or continuous medium with defects. In the past decades, DEM has widely been used, and several software has been developed, such as EDEM and PFC [3-5]. Many scholars have applied it to analyze the performance of asphalt mixture successfully. In 1992, Rothenburg and Bathurst [6] established a DEM model of asphalt mixture using a series of plane particles and the simulation results showed that $60 \%$ of the unconfined compressive strength was contributed by the bonding between particles and the remaining $40 \%$ was provided by the 
friction action between particles. In 2000, Buttlar and You [7] established a DEM model using two-dimensional fiber element, and the simulation results showed that the uniaxial compressive strength of asphalt concrete was $40 \%$ larger than the laboratory test results. In 2005, You and Buttlar analyzed the dynamic modulus of asphalt mixture basing on a two-dimensional DEM. The results showed that simulation results for relatively thick asphalt mixture were in good agreement with test results [8].

Dondi et al. $[9,10]$ used a round steel ball to develop cylinder specimens for triaxial test and simultaneously established discrete element models in the same size range. The study showed that the shape of coarse aggregate has a large influence on the strength of asphalt mixture. Hossian et al. [11] used a two-dimensional discrete element method to study the influence of the shape of aggregate on the mechanical properties of gravel mixtures. Yu and Shen [12-14] extended this method to the three-dimensional discrete element model. The study showed that increasing $2.36 \mathrm{~mm}$ or $4.75 \mathrm{~mm}$ passing ratio or reducing $9.5 \mathrm{~mm}$ passing ratio can improve the dynamic modulus of asphalt mixture. Yang et al. [15-18] analyzed and quantified the aggregate morphology and internal structures of computergenerated microstructural models of asphalt concrete. In the study, aggregate sphericity and angularity, air-void distribution, aggregate orientation, aggregate contact points, and aggregate distribution were analyzed based on the discrete element model.

DEM is also used to study the crack resistance and permanent deformation of asphalt mixture. For example, the discrete element method has been used to simulate the tensile test of disk specimens [19]. DEM was used to simulate a three-dimensional beam specimen and to reveal that the three-dimensional DEM can simulate crack initiation and propagation in the process of asphalt mixture's bending fracture [20]. In the literature [21-23], researchers used twodimensional DEM to simulate the creep law of asphalt mixture.

In summary, DEM has widely been used to simulate the performance of asphalt mixture. At low temperature, the properties of asphalt mixture are regarded as elastic. While the elastic bond model can be used in DEM in such cases, values of the parameters in the bond model have not certainly been determined in the past research. For example, Jun and Xiaoming [24] used a value of stiffness in a two-dimensional parallel bond model as $3.6 \times 10^{11} \mathrm{~Pa} / \mathrm{m}$; Duanyi and Xi [25] used the two-dimensional parallel bond model's stiffness as $1 \times 10^{14} \mathrm{~Pa} / \mathrm{m}$ and bond strength as $3 \times 10^{5} \mathrm{~Pa}$, the stiffness of contact bond model is $8 \times 10^{11} \mathrm{~N} / \mathrm{m}$, bond strength is $1 \times 10^{5} \mathrm{~N}$; and Fan [26] used the stiffness as $1.5 \times 10^{11} \mathrm{~N} / \mathrm{m}$ and the bond strength as $1.34 \times 10^{4} \mathrm{~N}$. These varying values of the parameters used in contact models lead to large differences in simulation results. In the authors' previous study, the splitting test was simulated basing on DEM and the influences of the bond model parameters on simulation results were analyzed [27]. In order to get reasonable simulation results, it is imperative to use appropriate values of the parameters. This study proposes a method to determine the parameters of a DEM-based contact bond model.

\section{Bond Model in DEM}

The contact bond model and parallel bond model are the most commonly used bond models in the discrete element method. The contact bond model considers that the contact between particles is only in a small region named point contact, as shown in Figure 1. The parallel bond model assumes that there is a certain contact range between particles, as shown in Figure 2. In the parallel bond model, force and moment can be transferred at the same time.

2.1. Contact Bond Model. The contact bond model can be regarded as a pair of springs acting on particles' contact point. Figure 3 shows the constitutive behavior relating the normal and shear components of contact force and relative displacement for particle contact occurring at the contact point. At any given time, either the contact bond model or the slip model is active. In Figure $3, F^{\mathrm{n}}$ is the normal contact force, where $F^{\mathrm{n}}>0$ indicates tension; $U^{\mathrm{n}}$ is the relative normal displacement, where $U^{\mathrm{n}}>0$ indicates the overlap; $F^{s}$ is the magnitude of the total shear contact force; and $U^{s}$ is the magnitude of the total shear displacement measured relative to the location of the contact point when the contact bond is formed.

When the overlap amount between particles is less than zero, tension is allowed to appear, but the normal tension cannot exceed the normal bond strength. When the normal tension is greater than or equal to the normal bond strength, the normal and tangential contact forces will be zero. When the tangential contact force is greater than or equal to the tangential bond strength, the tangential bond will be destroyed; however, if the tangential force does not exceed the friction limit, the tangential force will not change. In the contact bond model, four parameters are needed: normal stiffness $\left(k_{\mathrm{n}}\right)$, tangential stiffness $\left(k_{\mathrm{s}}\right)$, normal bond strength (n-bond), and tangential bond strength (s-bond). Because that contact bond acts only at the contact point, the unit of normal and shear stiffnesses, $k_{\mathrm{n}}$ and $k_{\mathrm{s}}$, is force/displacement and that of normal contact bond strength and shear contact bond strength, $\mathrm{n}$-bond and s-bond, is force.

2.2. Parallel Bond Model. The parallel bond model assumes that there is a medium material. The medium material is assumed as a set of springs with constant normal stiffness and tangent stiffness, which are distributed uniformly in the contact plane. The constitutive relationships of these springs are similar to those of point contact springs. However, one additional property is assumed, namely, transferring moment between particles. In the parallel model, normal and shear stiffnesses, $k_{\mathrm{n}}$ and $k_{\mathrm{s}}$, are expressed in units of stiffness per unit area. Thus, one must divide the stiffnesses of the contact bond model by the parallel bond cross-sectional area to obtain the stiffnesses of the parallel bond model. So in the parallel bond model, five parameters are defined: normal stiffness $\left(\mathrm{pb} \_k_{\mathrm{n}}\right)$ and shear stiffness $\left(\mathrm{pb} \_k_{\mathrm{s}}\right)$ expressed by stress/displacement; normal strength (pb_nstr) and shear strength (pb_sstr) expressed by stress; and bond disk radius, $R$. 


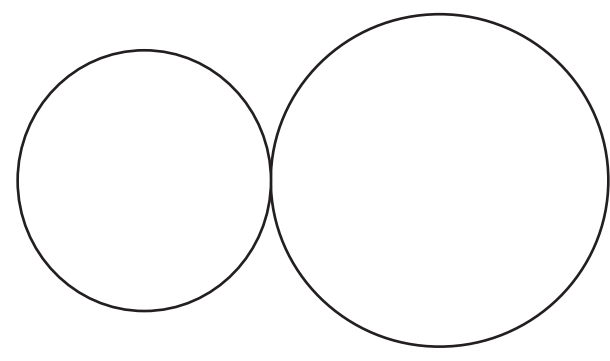

FIgURE 1: Contact bond model [27].

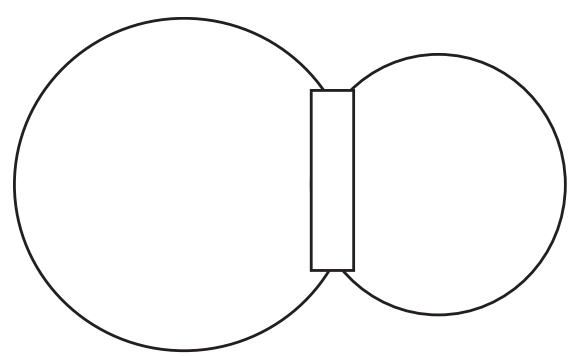

Figure 2: Parallel bond model [27].

\section{DEM-Based Splitting Test Model of Asphalt Mixture and Influencing Factors}

3.1. DEM Model of Splitting Test. The objective of this paper was to determine the parameter's value of the DEM bond model by simulating a splitting test. Therefore, it is necessary to artificially generate a test specimen that replicates an idealized asphalt mixture specimen. It is important that the sample is initially isotropic and exhibits approximately the same packing characteristics (volumetric proportions) as the idealized mixture. The following procedure was developed to prepare samples for later DEM simulation.

(i) The volume (area) of spherical (disk) particles was calculated according to the gradation of real aggregate in asphalt mixture, and the number of particles was determined

(ii) Boundaries which enclose the required space were generated, and the number of particles calculated above was generated randomly inside the space

(iii) Equilibrium calculation was required to make the particles reorient by cycling and decreasing the internal stress between particles to isotropic

(iv) Reducing the particles' radius slightly to decrease the level of isotropic stress until the stress was relatively low

(v) Particles with less than four contacts were detected and were expanded slightly to create additional contacts with neighboring particles

(vi) Certain contact model was selected and applied to contact points

(vii) The walls used as particles boundary were removed
Two types of asphalt mixture, namely, AC-13 and AC20 , were produced by DEM including two-dimensional and three-dimensional models. Taking the AC-13 type asphalt mixture as an example, the DEM sample in two and three dimensions are shown in Figure 4. When the splitting test was simulated, the load was applied by moving a loading plate (wall), and the reaction force and the displacement of loading plate were recorded until the sample failed. The models simulating the splitting test are shown in Figure 5.

\subsection{Analysis of Influencing Factors of the Discrete Element Model for Splitting Test}

3.2.1. Influence of Minimum Size of Particles. The aggregate used in asphalt mixture is formed by combining a certain gradation, and hence, the aggregate particles vary in size. However, the minimum size of particles of asphalt mixture must be determined when DEM is used. If the minimum particle size is too large, the real aggregate gradation cannot be reflected fully. On the contrary, if the minimum particle size selected is too small, the simulating process will take too much time. Therefore, it is imperative to select an optimum value for the minimum particle size on the DEM. The following paragraph will present simulation results from the contact bond model and the parallel bond model to analyze the effect of the minimum particle size.

The influence of minimum size of particles on simulation results was analyzed in the authors' previous study [27]. The minimum size of particles has a large influence on the simulation results when the contact bond model was used. However, when the parallel bond model was used, the influence of the minimum particle size was less evident. The reason causing difference between two bond models is the different assumptions. The contact bond model considers that the contact between particles acts at a point and the contact parameters can be set directly without considering particle size. If the contact bond model is used, a smaller minimum particle size should be selected, and if the parallel bond model is used, the minimum particle size can be selected according to the calculation efficiency. It should be noted that the microparameters (particle and bond stiffnesses and bond strengths) in the bond model can also be determined by the corresponding macroresponses (such as elastic modulus and peak strength). When the method is used, the effect of minimum particle size can be reduced in the contact bond model.

3.2.2. Influence of Contact Bond Model Parameters. The influence of the contact bond parameters on the simulation results is shown in Figure 6. As shown in Figure 6(a), the slope of the load-displacement curve increased gradually with an increase in stiffness and the peak load increased too. The results illustrate that if the stiffness is set too large, the simulated material possesses relatively large modulus and higher strength. On the contrary, if the parameter stiffness is set too low, the simulated material possesses a lower modulus and good displacement resistance. As shown in 


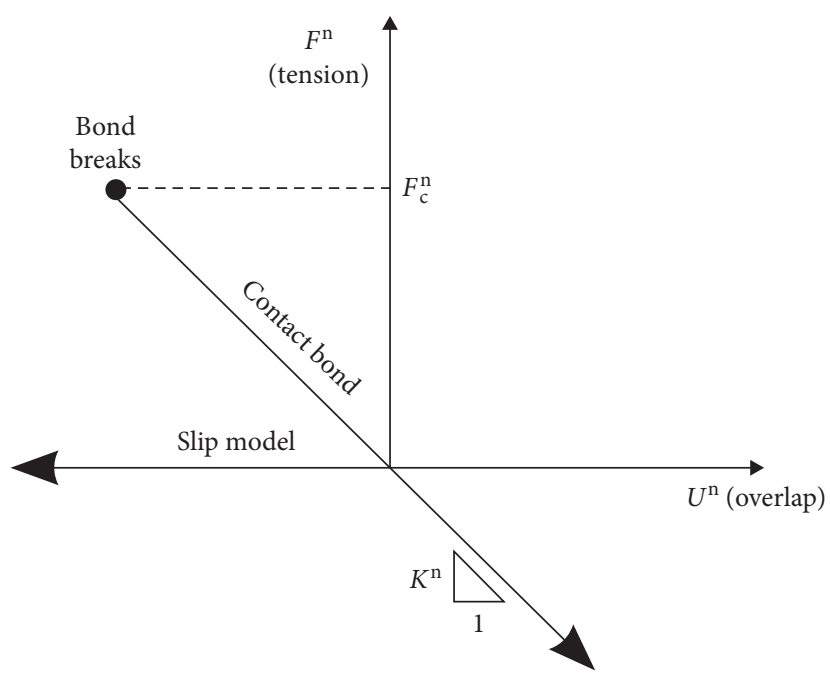

(a)

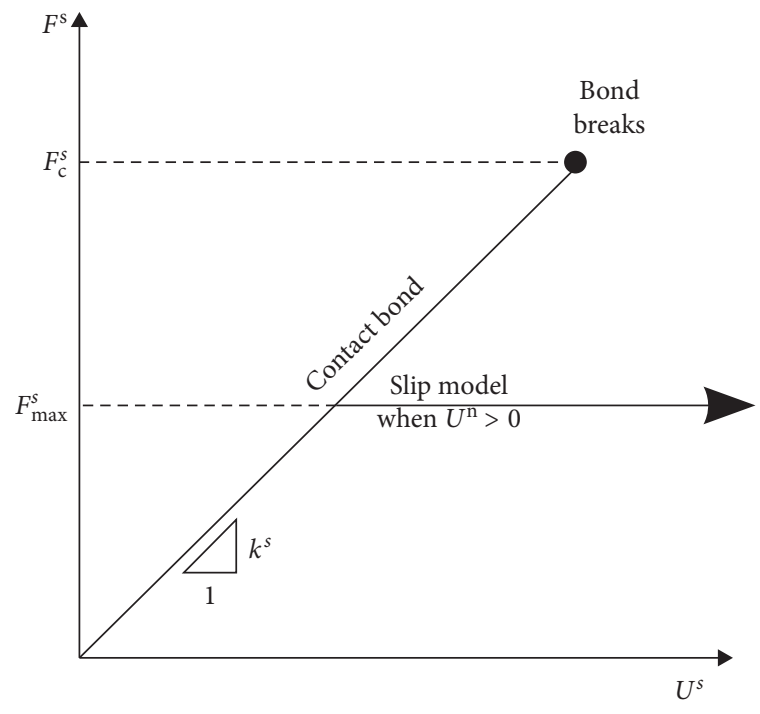

(b)

Figure 3: Constitutive behavior for contact occurring at a point. (a) Normal component and (b) shear component of contact force.

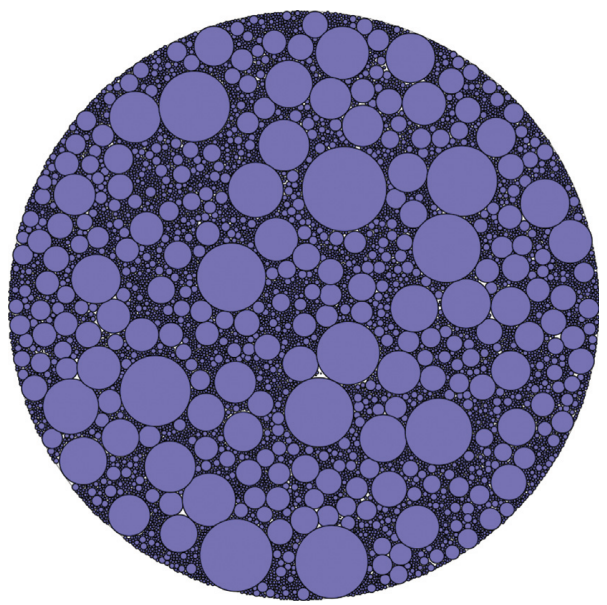

(a)

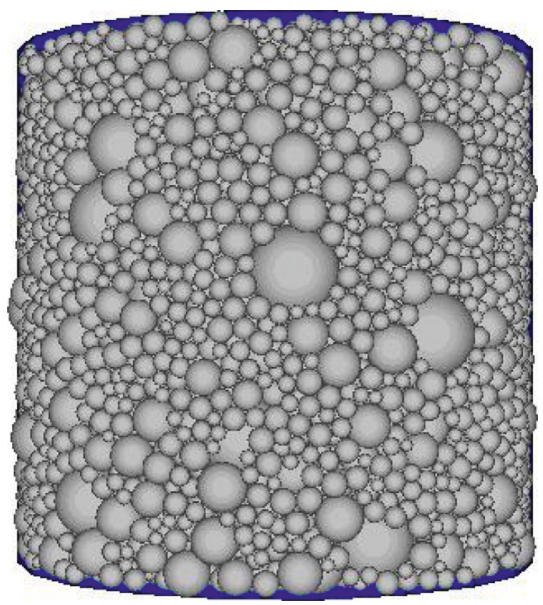

(b)

Figure 4: Splitting test sample divided into discrete elements. (a) Two-dimensional disk specimen. (b) Three-dimensional sphere specimen [27].

Figure 6(b), when the bond strength is varied, the peak load increases with an increase in bond strength. However, the gradient of the loading-displacement curve changed insignificantly with an increase in the bond strength. Thus, the slope of the loading-displacement curve at the beginning stage is mainly affected by the stiffness parameters and the peak load is determined both by the stiffness and bond strength parameters.

3.2.3. Influence of Parallel Bond Model Parameters. The simulation results using the parallel bond model are plotted in Figure 7. As shown in Figure 7(a), with an increase in the stiffness of the parallel bond model, the slope of the load-displacement curve increased correspondingly which is similar to the results from the contact bond model. However, with an increase in the contact stiffness, the peak load decreased, which is contrary to the results from the contact bond model. As shown in Figure 7(b), the peak load increased with an increase in the bond strength; however, the slope of the loaddisplacement curve was close at the beginning stage, which is similar to the results from the contact bond model. In conclusion, when the parallel bond model is used, the slope of the load-displacement curve at the beginning stage is determined by using the contact stiffness and the peak load is mainly determined by using the bond strength parameters. 


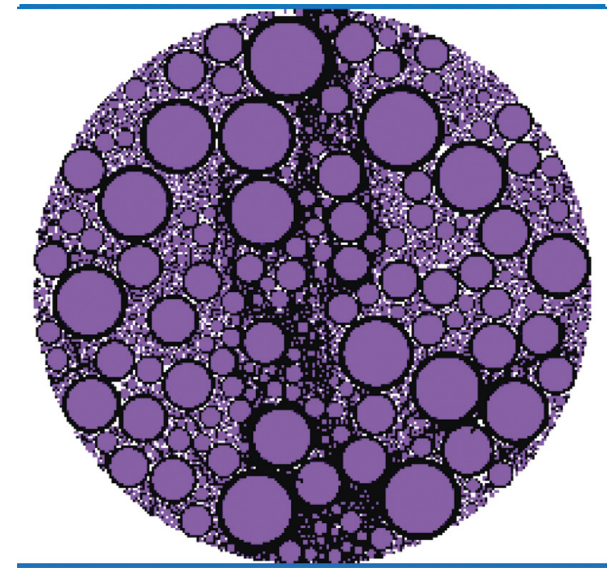

(a)

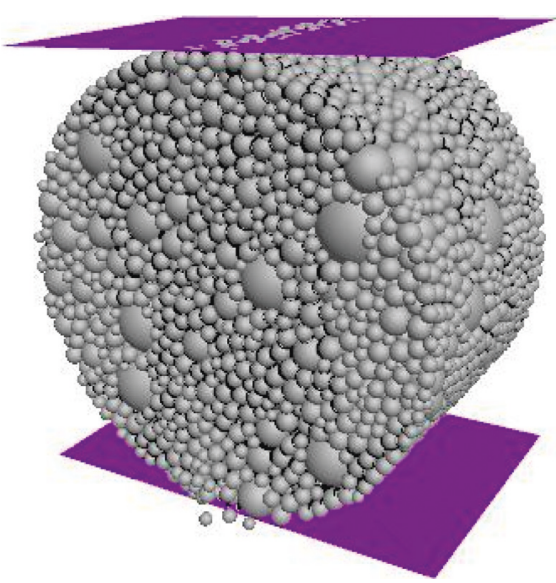

(b)

FIGURE 5: Simulating the splitting test by DEM. (a) Two-dimensional model. (b) Three-dimensional model.

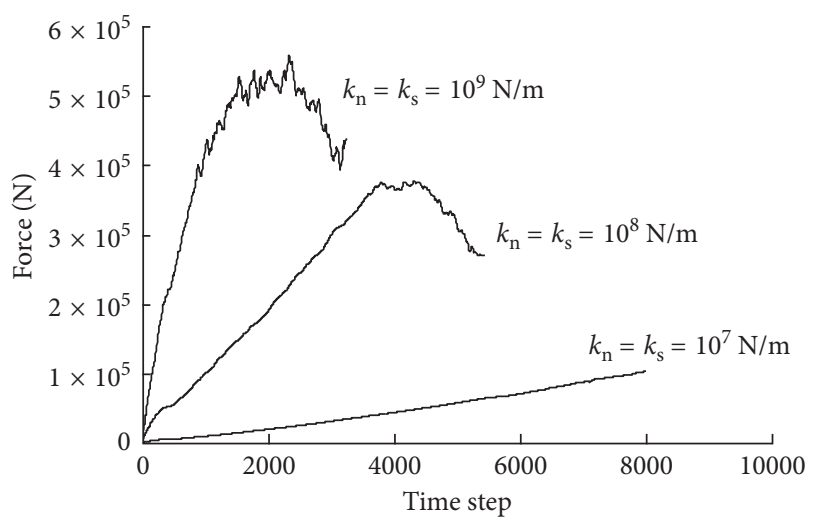

(a)

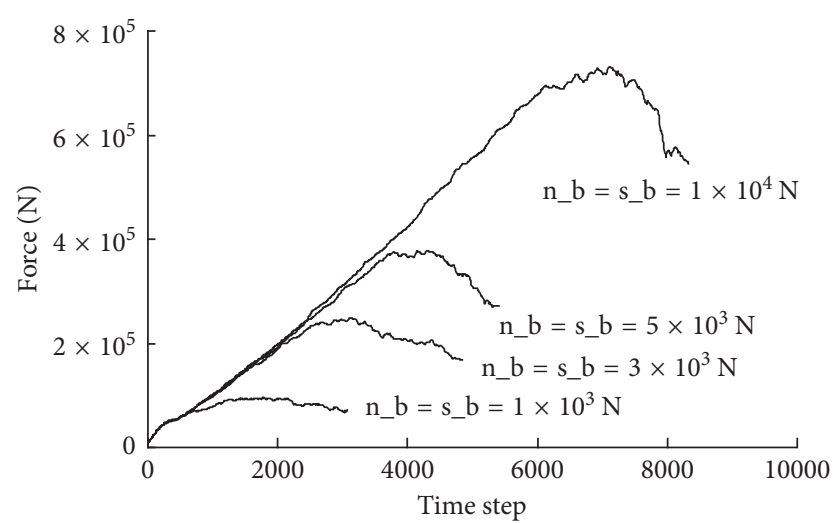

(b)

Figure 6: Effect of the contact bond model parameters. (a) Effect of stiffness. (b) Effect of bond strength [27].

\section{Experimental Determination of Parameters of DEM Bond Model Based on Splitting Test}

4.1. Splitting Test. The asphalt used for the test was 70\# according to the penetration test, and the aggregates and fillers were limestone from Shandong province in China. The specimen was cylindrical with the diameter of $101.6 \mathrm{~mm}$ and the height of $63.5 \mathrm{~mm}$ compacted by the Marshall compaction test. Two types of asphalt mixtures, namely, AC-13 and AC-20, were prepared. The gradation of AC-13 and AC-20 is listed in Table 1. According to the Marshall design method of asphalt mixture, the best asphalt content of AC-20 was $4.3 \%$ and AC-13 was $5 \%$. The splitting tests were done at lower temperature, namely, $-10^{\circ} \mathrm{C}, 0^{\circ} \mathrm{C}, 10^{\circ} \mathrm{C}$, and $20^{\circ} \mathrm{C}$. The prepared specimen and splitting process are shown in Figure 8.

During the test, the loading speed had a significant influence on the test results. According to Chinese test standard JTG E20-2011, the loading speed was set to
$1 \mathrm{~mm} / \mathrm{min}$ when the temperature was $-10^{\circ} \mathrm{C}$ or $0^{\circ} \mathrm{C}$ and $5 \mathrm{~mm} / \mathrm{min}$ when the temperature was $10^{\circ} \mathrm{C}$ or $20^{\circ} \mathrm{C}$. The splitting test results are plotted in Figures 9 and 10.

4.2. Determination of the DEM Bond Model Parameters of Asphalt Mixture. Section 2 discussed that the variation in the bond model parameters of DEM clearly affects the slope and peak load of the simulation loading-displacement curve. Unreasonable model parameters will lead to too much deviation between simulated and actual test results. The parameters of the DEM bond model can be determined in two steps. Firstly, the relationship between loaddisplacement curve characteristics and bond model parameters were derived from DEM simulation results and are plotted as shown in Figures 11-14. Secondly, the slope and peak load were extracted from actual the loaddisplacement curve from the splitting test and were compared with the simulation relationships as presented in Figures 11-14. For example, according to the slope of the actual load-displacement curve, the stiffness of the $2 \mathrm{D}$ 


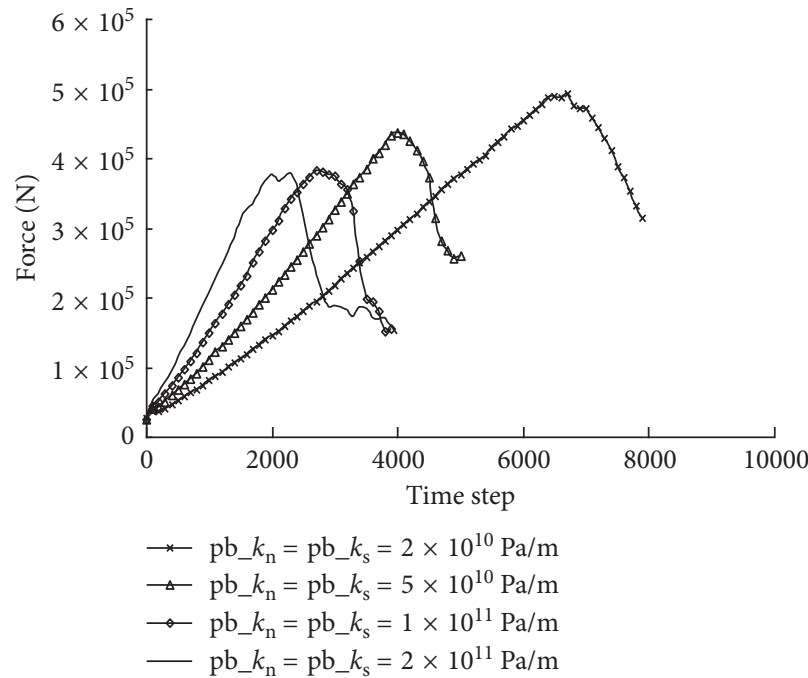

(a)

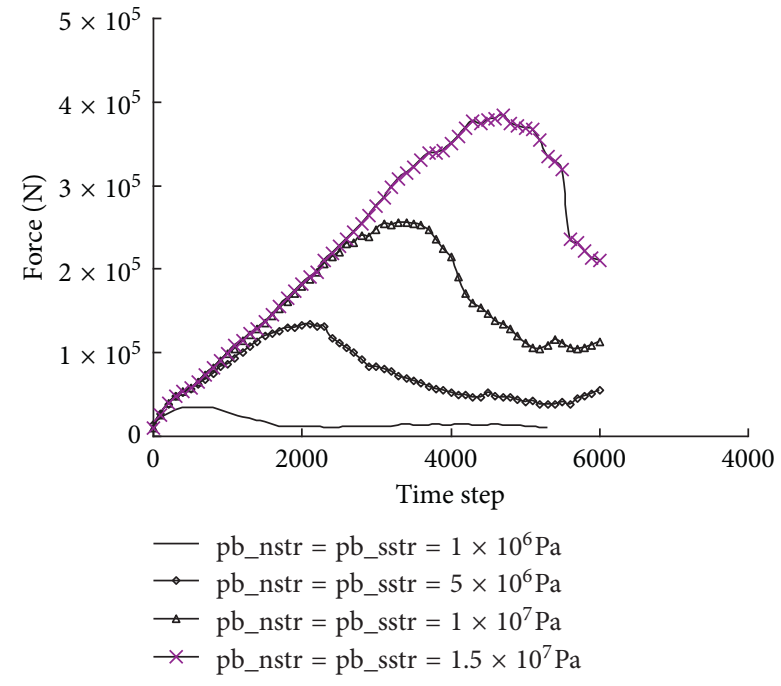

(b)

FiguRE 7: Influence of the parallel bond model parameters. (a) Effect of stiffness. (b) Effect of bond strength [27].

TABLE 1: Gradation of the aggregate for asphalt mixture.

\begin{tabular}{lccccccccccc}
\hline \multicolumn{10}{c}{ Sieve pass rate (\%) } \\
\hline Sieve size $(\mathrm{mm})$ & 19 & 16 & 13.2 & 9.5 & 4.75 & 2.36 & 1.18 & 0.6 & 0.3 & 0.15 & 0.075 \\
AC-13 & & 100 & 95 & 76.5 & 53 & 37 & 26.5 & 19 & 13.5 & 10 & 6 \\
AC-20 & 100 & 85 & 71 & 61 & 41 & 30 & 22.5 & 16 & 11 & 8.5 & 5 \\
\hline
\end{tabular}

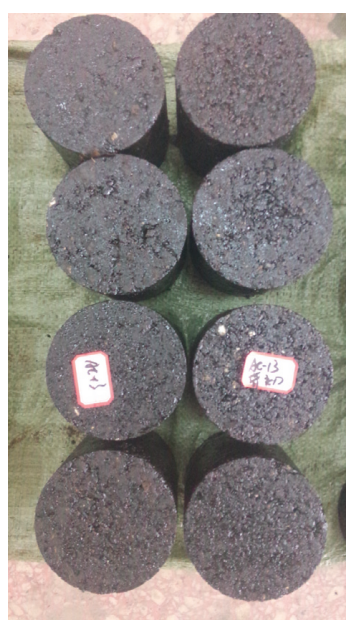

(a)

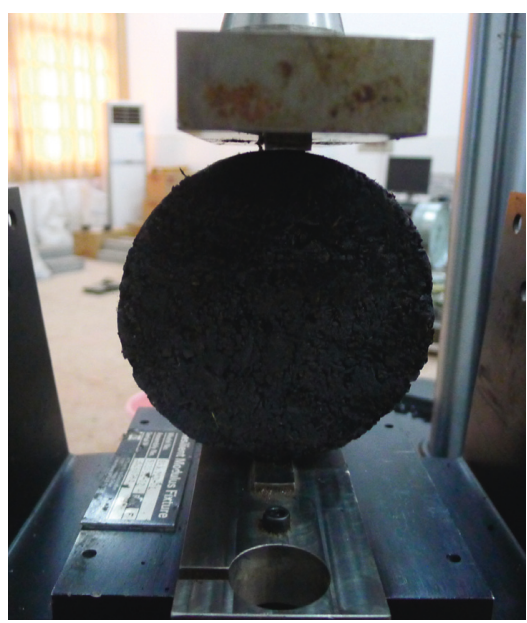

(b)

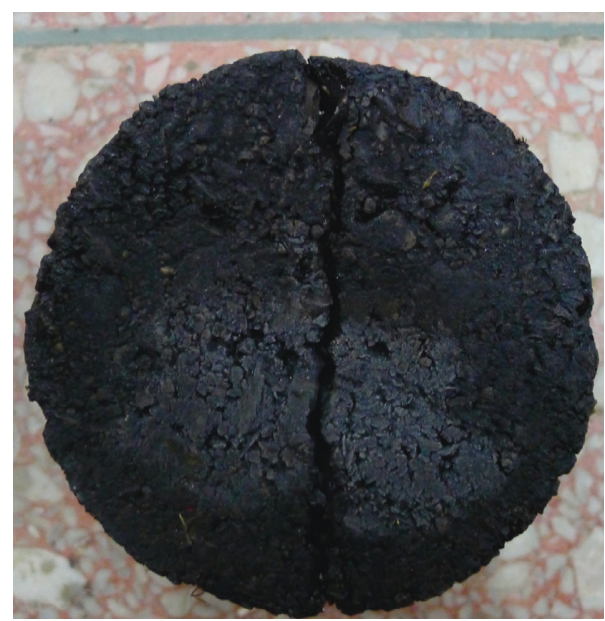

(c)

Figure 8: Splitting test. (a) AC-13 specimen. (b) Splitting test loading. (c) Failure mode of the splitting test.

contact bond model was achieved as shown in Figure 11(a), and then the real test peak load was compared as shown in Figure 11(b) and the bond strength of the $2 \mathrm{D}$ contact bond model was achieved. Using the same method, all of the parameters of the DEM bond model were obtained. By comparing the slope value and peak load with the parameters from Figures 11-14, the parameters of 2D and 3D DEM bond models were obtained. The values of the bond model parameters at several temperatures are listed in Tables 2 and 3.

4.3. Comparison of Laboratory Splitting Test and Discrete Element Method. A DEM model was established using the parameters in Table 2 to simulate the splitting test of $\mathrm{AC}-20$. The comparison results for $\mathrm{AC}-20$ at $0^{\circ} \mathrm{C}$ are shown in Figure 15. As can be seen from the plots, the 


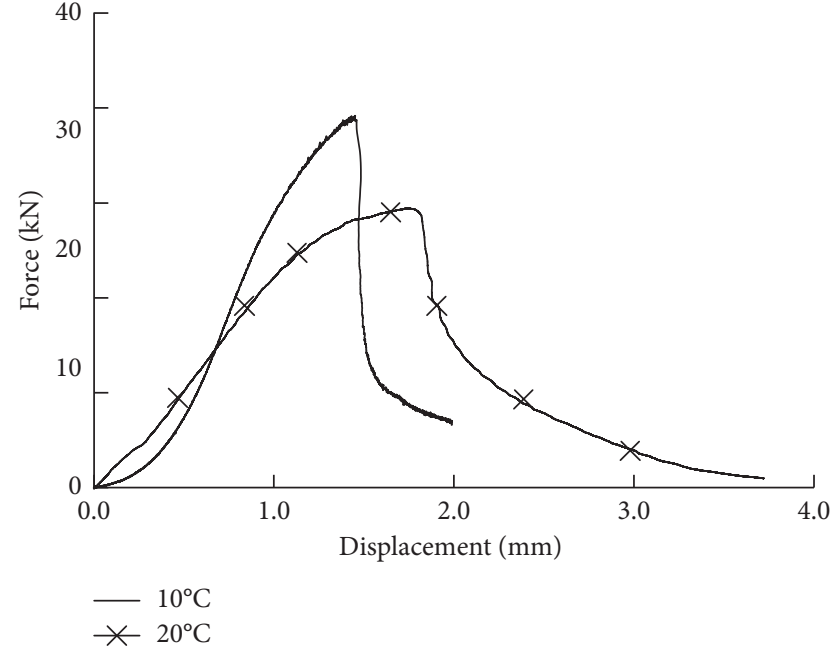

(a)

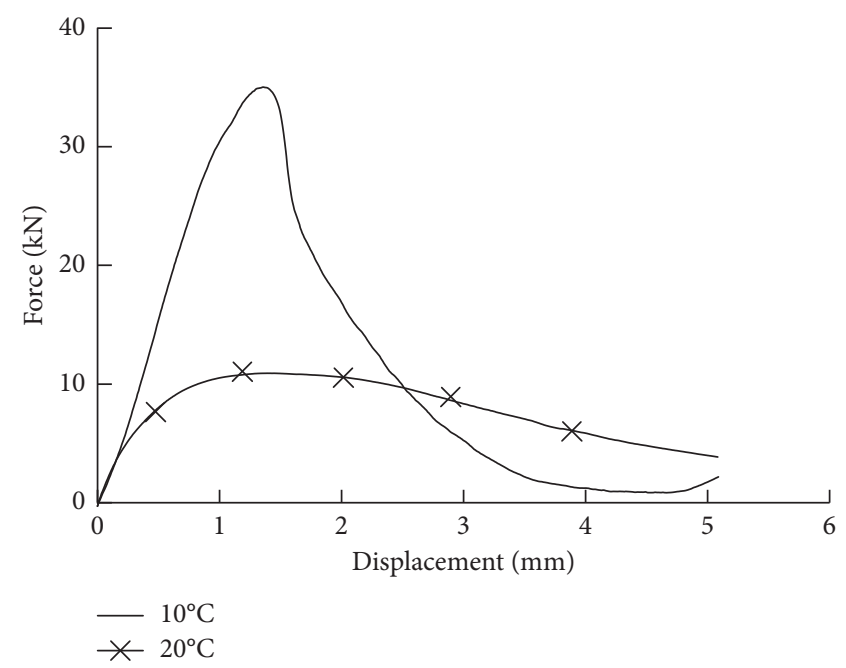

(b)

Figure 9: Splitting test results of AC-20. Load-displacement curve: (a) $-10^{\circ} \mathrm{C}$ and $0^{\circ} \mathrm{C}$ and (b) $10^{\circ} \mathrm{C}$ and 20 $0^{\circ} \mathrm{C}$ [27].

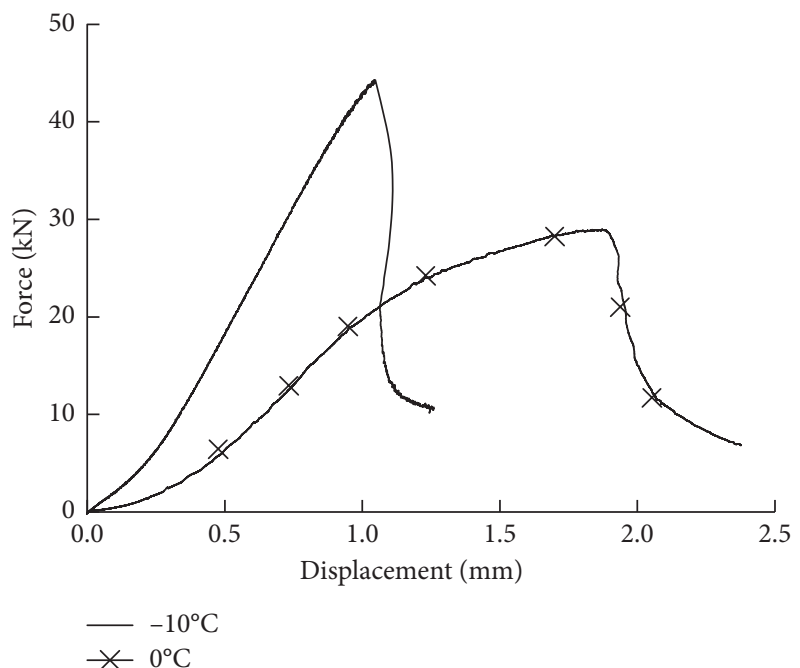

(a)

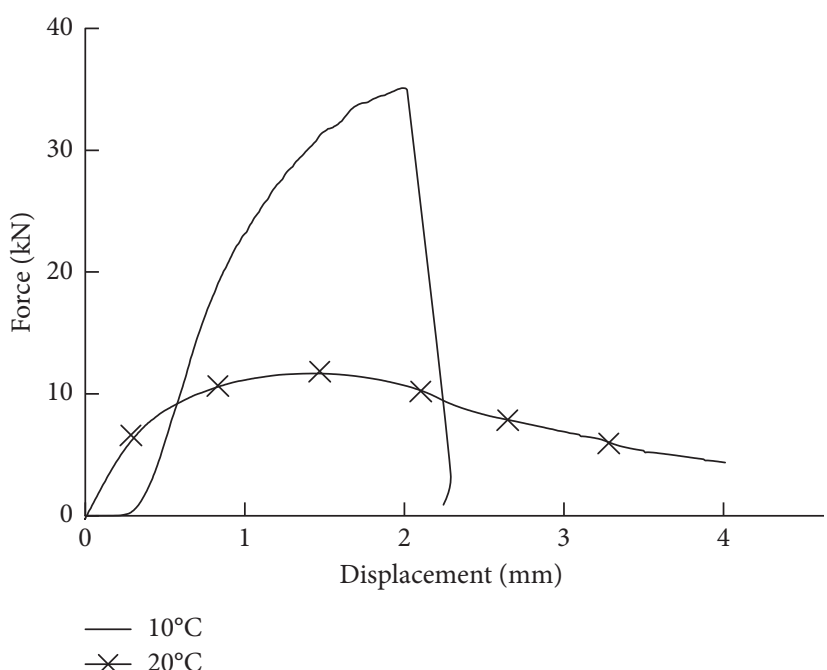

(b)

Figure 10: Splitting test results of AC-13. Load-displacement curve: (a) $-10^{\circ} \mathrm{C}$ and $0^{\circ} \mathrm{C}$ and (b) $10^{\circ} \mathrm{C}$ and $20^{\circ}$.

two-dimensional and three-dimensional discrete element method simulation results are close to the test results. It should be noted that the displacement corresponding to the peak load is larger than the test value, except that the result of three-dimensional parallel bond model is close to the actual test result. Therefore, the parallel bond model is better to simulate the load-displacement behavior of asphalt mixture than the contact bond model. Because of that the voids between coarse aggregate in asphalt mixture are filled by fine aggregate and asphalt sand which is regarded as the medium material between particles. Therefore, the use of the parallel bond model between particles is more reasonable compared to the contact bond model.

Figure 16 compares the results for the AC-20 specimen at $10^{\circ} \mathrm{C}$ between laboratory test and simulation. From the figure, the same conclusion can be obtained; that is, the use of the parallel bond model is more reasonable compared to the contact bond model.

In addition, the behavior of the asphalt mixture at low temperature in the laboratory test is that the load value decreased rapidly after it reached a peak point; however, the discrete element simulation result showed that the load value decreased slowly after it reached the peak point. Therefore, it can be concluded that the DEM bond models discussed in this paper are unable to simulate brittle failure process of asphalt mixture.

\section{Conclusion}

In this study, the method for determining the parameters of a discrete element was studied based on the asphalt mixture splitting test. The main conclusions are as follows: 


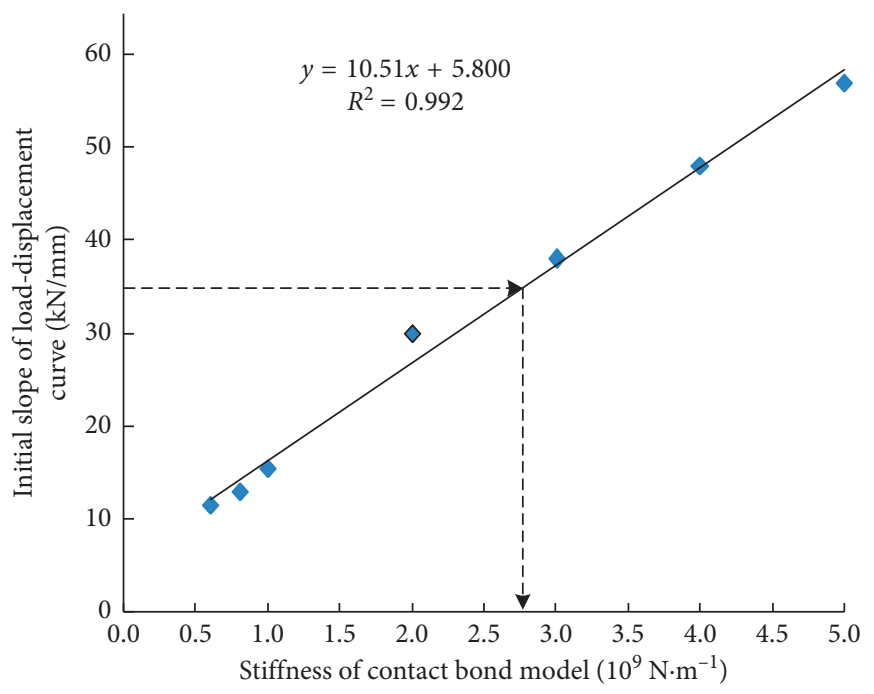

(a)

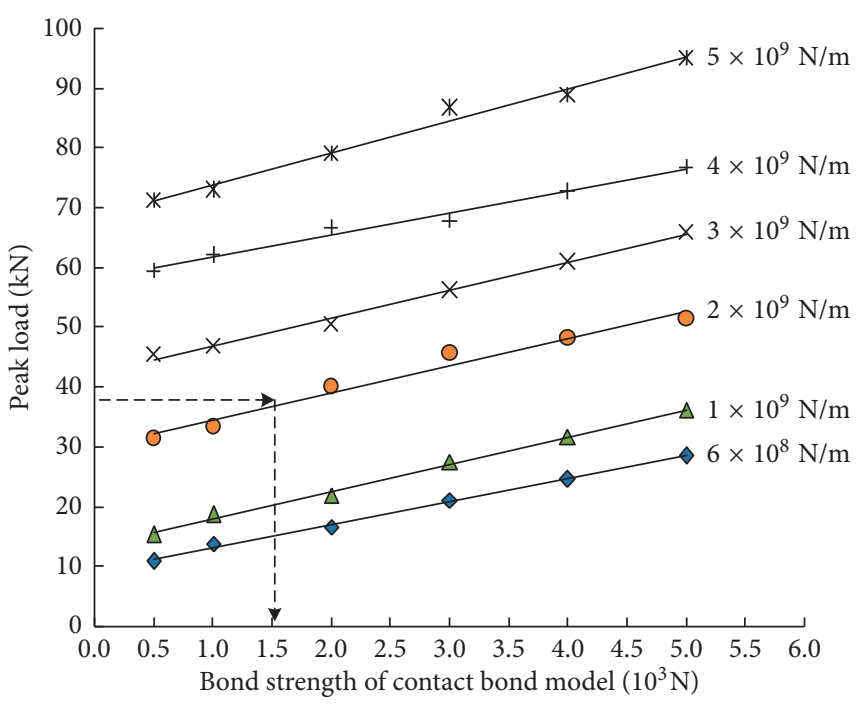

(b)

FIgure 11: Parameters of the 2D contact bond model. (a) Original slope of the simulated splitting test curve versus stiffness. (b) Peak load of the simulated splitting test versus bond strength.

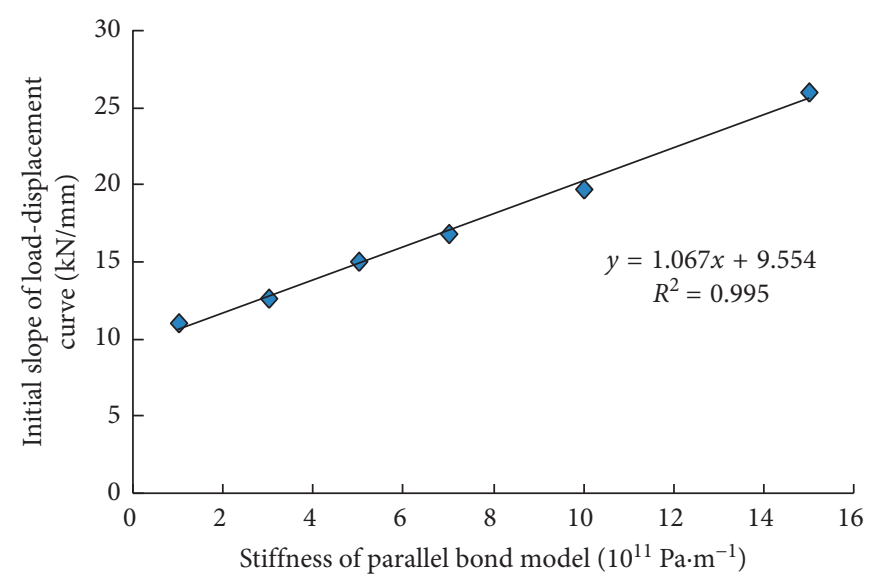

(a)

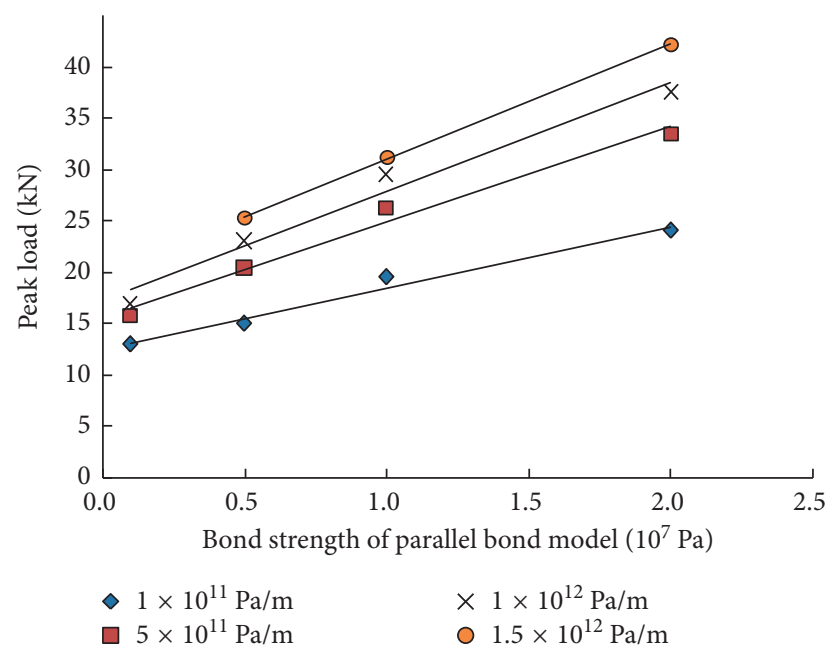

(b)

Figure 12: Parameters of the 2D parallel bond model. (a) Original slope of the splitting test curve versus stiffness. (b) Peak load of the splitting test versus bond strength.

(i) When the parameters in the DEM bond model were set constant, the simulation results were affected by the minimum particle size if the contact bond model was used. However, minimum particle size had little effect on simulation results when using the parallel bond model. Therefore, when the contact bond model is used, it is best to select appropriate particle size and model parameters on the basis of calculation efficiency and precision.

(ii) Basing on the simulation results of the splitting test, the slope of the load-displacement curve at the elastic stage was closely related to the stiffness parameters of the bond model. The greater the stiffness, the larger was the slope. The bond strength parameters in both contact bond and parallel bond models had a large influence on the peak load of the simulation results. The peak load in the loaddisplacement curve increased with the increase in the bond strength parameters' value.

(iii) According to the influence of the bond model parameters on the DEM simulation results, the relationships between slope of the loaddisplacement curve at the beginning stage, the peak load and the bond model parameters of stiffness, and bond strength was established. By comparing the initial slop and peak load of the load-displacement curve of simulation with the actual splitting test results, the parameter values of 


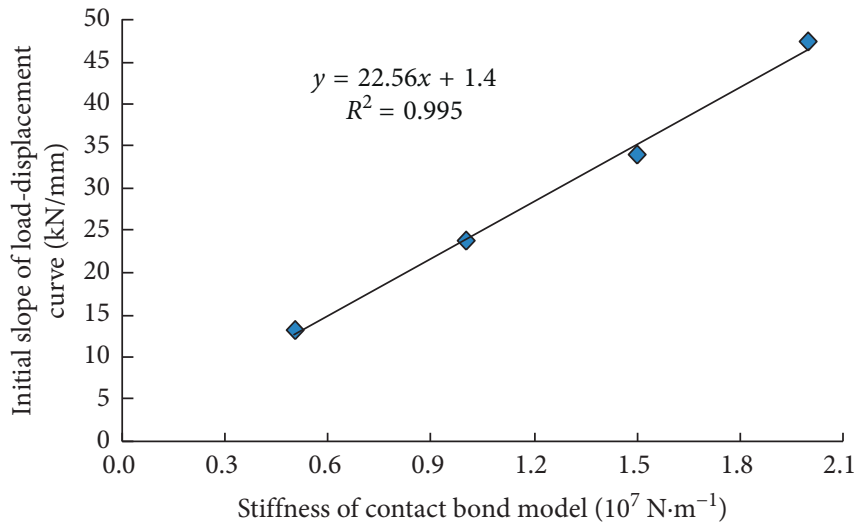

(a)

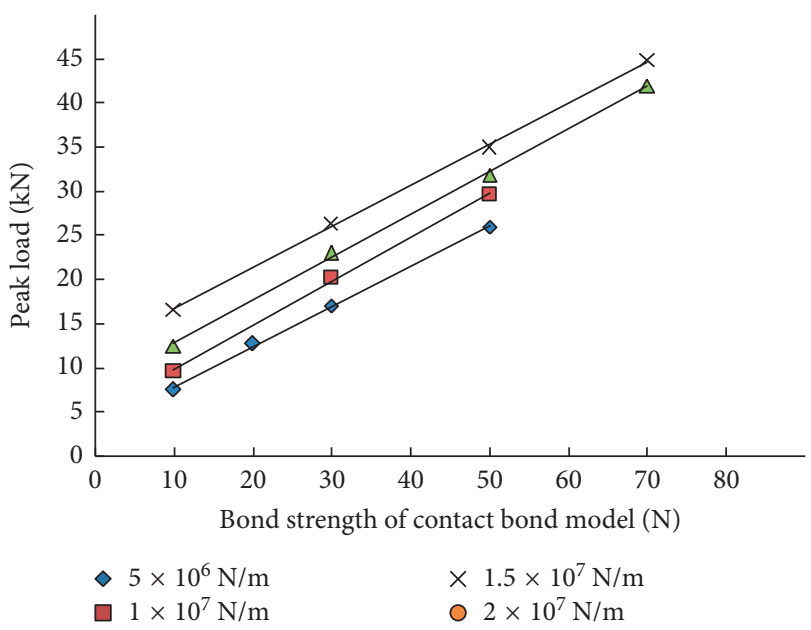

(b)

Figure 13: Parameters of the 3D contact bond model. (a) Original slope of the splitting test curve versus stiffness. (b) Peak load of the splitting test versus bond strength.

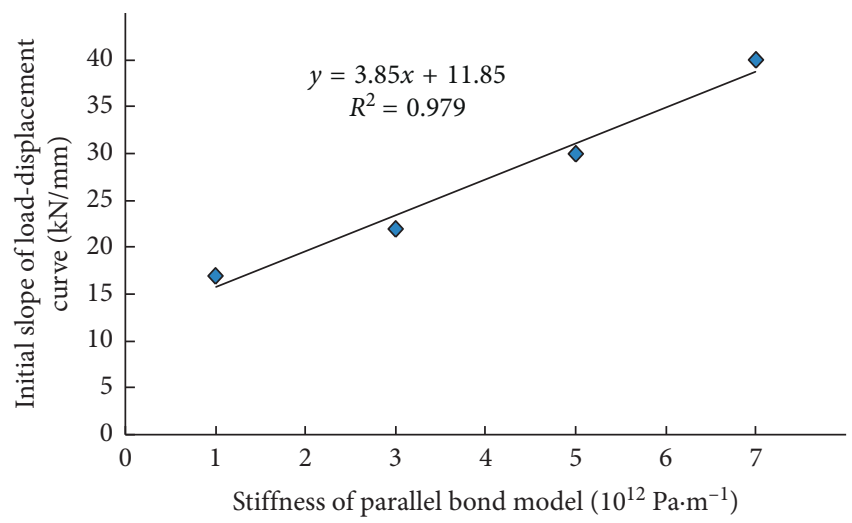

(a)

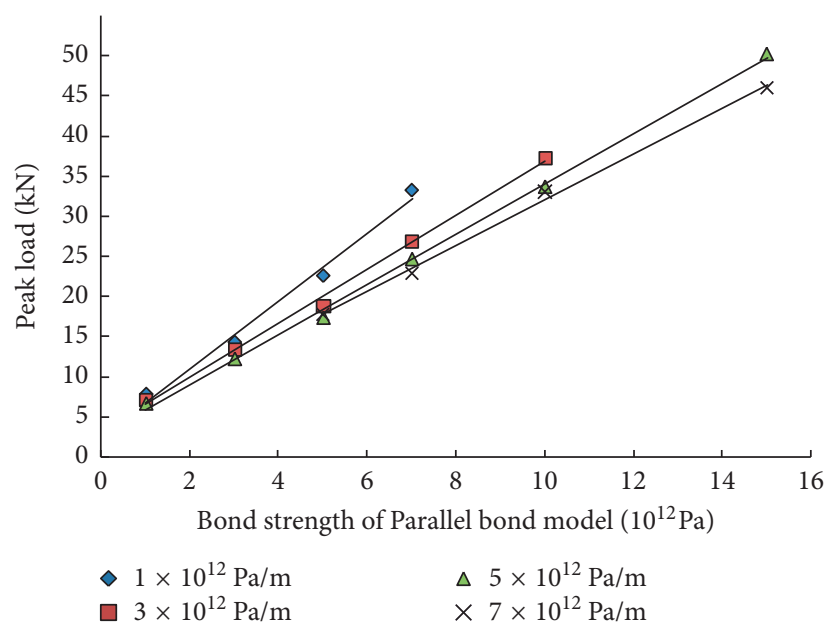

(b)

Figure 14: Parameters of the 3D parallel bond model. (a) Original slope of the splitting test curve versus stiffness. (b) Peak load of the splitting test versus bond strength.

TABLe 2: Discrete bond model parameters of AC-20.

\begin{tabular}{|c|c|c|c|c|}
\hline Temperature & & Contact type & Stiffness & Bond strength \\
\hline$-10^{\circ} \mathrm{C}$ & $3 \mathrm{D}$ & $\begin{array}{l}\text { Contact bond model } \\
\text { Parallel bond model } \\
\text { Contact bond model } \\
\text { Parallel bond model }\end{array}$ & $\begin{array}{c}2.2 \times 10^{9} \mathrm{~N} \cdot \mathrm{m}^{-1} \\
1.6 \times 10^{12} \mathrm{~Pa} \cdot \mathrm{m}^{-1} \\
2.8 \times 10^{7} \mathrm{~N} \cdot \mathrm{m}^{-1} \\
3.9 \times 10^{12} \mathrm{~Pa} \cdot \mathrm{m}^{-1}\end{array}$ & $\begin{array}{c}1.8 \times 10^{2} \mathrm{~N} \\
5.8 \times 10^{7} \mathrm{~Pa} \\
72.0 \mathrm{~N} \\
1.1 \times 10^{8} \mathrm{~Pa}\end{array}$ \\
\hline $0^{\circ} \mathrm{C}$ & $3 \mathrm{D}$ & $\begin{array}{l}\text { Contact bond model } \\
\text { Parallel bond model } \\
\text { Contact bond model } \\
\text { Parallel bond model }\end{array}$ & $\begin{array}{c}1.5 \times 10^{9} \mathrm{~N} \cdot \mathrm{m}^{-1} \\
1.0 \times 10^{12} \mathrm{~Pa} \cdot \mathrm{m}^{-1} \\
9.0 \times 10^{6} \mathrm{~N} \cdot \mathrm{m}^{-1} \\
2.7 \times 10^{12} \mathrm{~Pa} \cdot \mathrm{m}^{-1} \\
\end{array}$ & $\begin{array}{c}2.0 \times 10^{2} \mathrm{~N} \\
2.0 \times 10^{7} \mathrm{~Pa} \\
52.0 \mathrm{~N} \\
7.5 \times 10^{7} \mathrm{~Pa} \\
\end{array}$ \\
\hline $10^{\circ} \mathrm{C}$ & $3 \mathrm{D}$ & $\begin{array}{l}\text { Contact bond model } \\
\text { Parallel bond model } \\
\text { Contact bond model } \\
\text { Parallel bond model }\end{array}$ & $\begin{array}{c}2.3 \times 10^{9} \mathrm{~N} \cdot \mathrm{m}^{-1} \\
1.9 \times 10^{12} \mathrm{~Pa} \cdot \mathrm{m}^{-1} \\
1.3 \times 10^{7} \mathrm{~N} \cdot \mathrm{m}^{-1} \\
4.7 \times 10^{12} \mathrm{~Pa} \cdot \mathrm{m}^{-1}\end{array}$ & $\begin{array}{c}1.3 \times 10^{2} \mathrm{~N} \\
1.1 \times 10^{7} \mathrm{~Pa} \\
61.0 \mathrm{~N} \\
1.1 \times 10^{8} \mathrm{~Pa}\end{array}$ \\
\hline $20^{\circ} \mathrm{C}$ & $3 \mathrm{D}$ & $\begin{array}{l}\text { Contact bond model } \\
\text { Parallel bond model } \\
\text { Contact bond model } \\
\text { Parallel bond model }\end{array}$ & $\begin{array}{c}1.4 \times 10^{9} \mathrm{~N} \cdot \mathrm{m}^{-1} \\
9.8 \times 10^{11} \mathrm{~Pa} \cdot \mathrm{m}^{-1} \\
1.1 \times 10^{7} \mathrm{~N} \cdot \mathrm{m}^{-1} \\
3.4 \times 10^{12} \mathrm{~Pa} \cdot \mathrm{m}^{-1}\end{array}$ & $\begin{array}{c}- \\
- \\
10.0 \mathrm{~N} \\
2.0 \times 10^{7} \mathrm{~Pa}\end{array}$ \\
\hline
\end{tabular}


TABLE 3: Discrete bond model parameters of AC-13.

\begin{tabular}{|c|c|c|c|c|}
\hline Temperature & & Contact type & Stiffness & Bond strength \\
\hline$-10^{\circ} \mathrm{C}$ & $3 \mathrm{D}$ & $\begin{array}{l}\text { Contact bond model } \\
\text { Parallel bond model } \\
\text { Contact bond model } \\
\text { Parallel bond model }\end{array}$ & $\begin{array}{c}4.2 \times 10^{9} \mathrm{~N} \cdot \mathrm{m}^{-1} \\
3.8 \times 10^{12} \mathrm{~Pa} \cdot \mathrm{m}^{-1} \\
2.2 \times 10^{7} \mathrm{~N} \cdot \mathrm{m}^{-1} \\
9.9 \times 10^{12} \mathrm{~Pa} \cdot \mathrm{m}^{-1}\end{array}$ & $\begin{array}{c}9.0 \times 10^{2} \mathrm{~N} \\
3.9 \times 10^{7} \mathrm{~Pa} \\
69.0 \mathrm{~N} \\
1.6 \times 10^{8} \mathrm{~Pa}\end{array}$ \\
\hline $0^{\circ} \mathrm{C}$ & $3 \mathrm{D}$ & $\begin{array}{l}\text { Contact bond model } \\
\text { Parallel bond model } \\
\text { Contact bond model } \\
\text { Parallel bond model }\end{array}$ & $\begin{array}{c}1.4 \times 10^{9} \mathrm{~N} \cdot \mathrm{m}^{-1} \\
9.8 \times 10^{11} \mathrm{~Pa} \cdot \mathrm{m}^{-1} \\
8.2 \times 10^{6} \mathrm{~N} \cdot \mathrm{m}^{-1} \\
2.8 \times 10^{12} \mathrm{~Pa} \cdot \mathrm{m}^{-1}\end{array}$ & $\begin{array}{c}3.5 \times 10^{2} \mathrm{~N} \\
1.3 \times 10^{7} \mathrm{~Pa} \\
54.0 \mathrm{~N} \\
6.7 \times 10^{7} \mathrm{~Pa}\end{array}$ \\
\hline $10^{\circ} \mathrm{C}$ & $3 \mathrm{D}$ & $\begin{array}{l}\text { Contact bond model } \\
\text { Parallel bond model } \\
\text { Contact bond model } \\
\text { Parallel bond model }\end{array}$ & $\begin{array}{c}1.8 \times 10^{9} \mathrm{~N} \cdot \mathrm{m}^{-1} \\
1.6 \times 10^{12} \mathrm{~Pa} \cdot \mathrm{m}^{-1} \\
1.1 \times 10^{7} \mathrm{~N} \cdot \mathrm{m}^{-1} \\
3.4 \times 10^{12} \mathrm{~Pa} \cdot \mathrm{m}^{-1}\end{array}$ & $\begin{array}{c}1.4 \times 10^{2} \mathrm{~N} \\
1.4 \times 10^{7} \mathrm{~Pa} \\
65.0 \mathrm{~N} \\
9.2 \times 10^{7} \mathrm{~Pa}\end{array}$ \\
\hline $20^{\circ} \mathrm{C}$ & $2 \mathrm{D}$ & $\begin{array}{l}\text { Contact bond model } \\
\text { Parallel bond model } \\
\text { Contact bond model } \\
\text { Parallel bond model }\end{array}$ & $\begin{array}{c}2.1 \times 10^{9} \mathrm{~N} \cdot \mathrm{m}^{-1} \\
1.7 \times 10^{12} \mathrm{~Pa} \cdot \mathrm{m}^{-1} \\
1.2 \times 10^{7} \mathrm{~N} \cdot \mathrm{m}^{-1} \\
4.2 \times 10^{12} \mathrm{~Pa} \cdot \mathrm{m}^{-1}\end{array}$ & $\begin{array}{c}- \\
- \\
13.0 \mathrm{~N} \\
2.8 \times 10^{7} \mathrm{~Pa}\end{array}$ \\
\hline
\end{tabular}

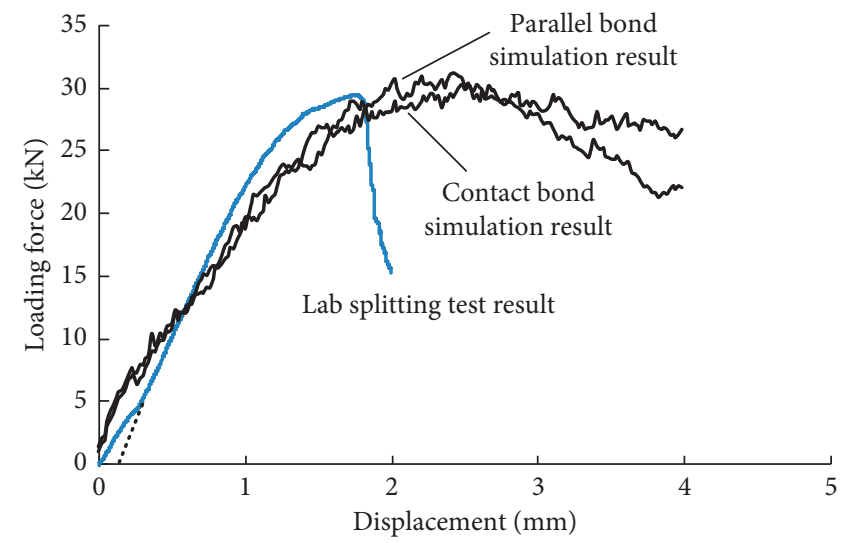

(a)

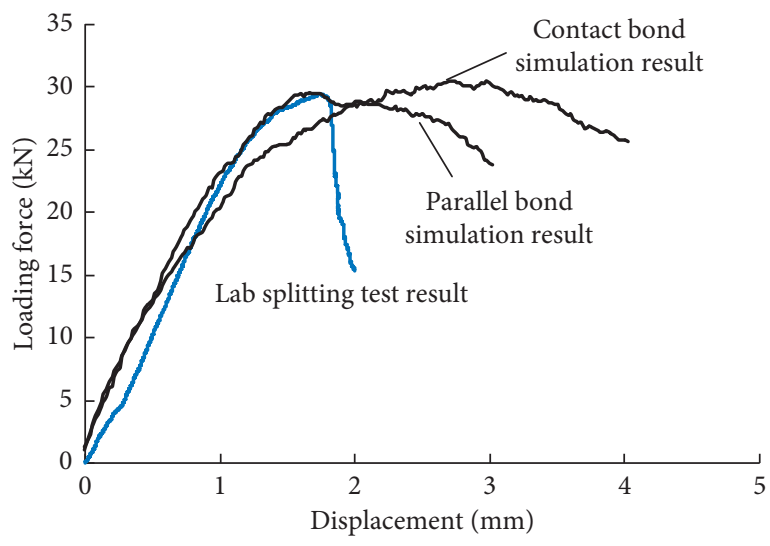

(b)

FIgURE 15: Comparison of the simulation results and lab test of AC-20 at $0^{\circ} \mathrm{C}$. (a) 2D model. (b) 3D model [27].

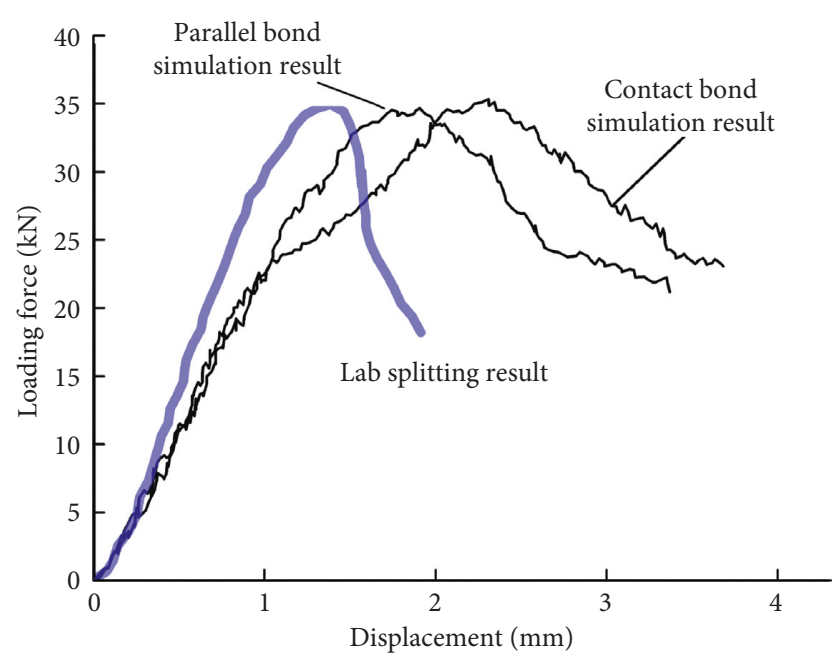

(a)

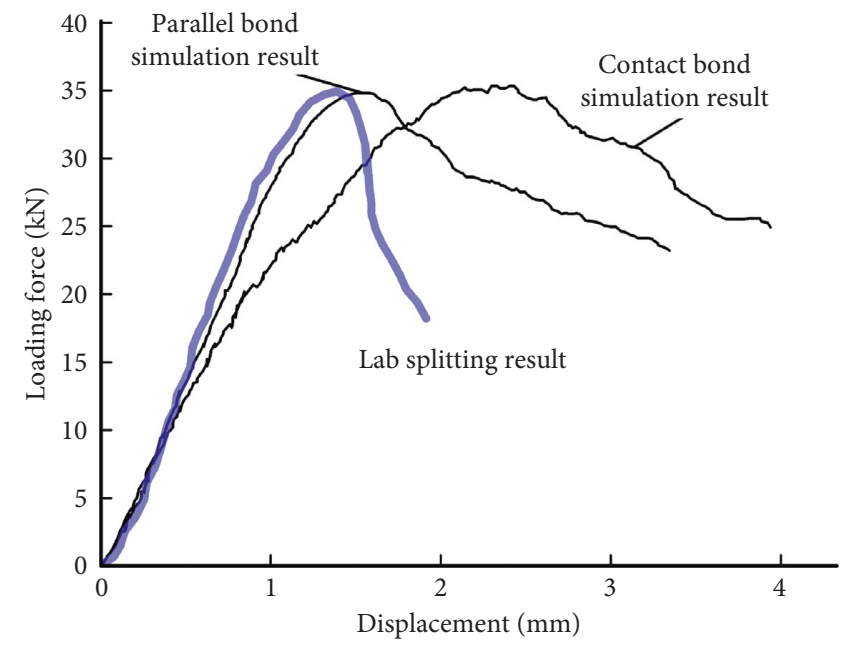

(b)

Figure 16: Comparison of the simulation results and lab test of AC-20 at $10^{\circ} \mathrm{C}$. (a) $2 \mathrm{D}$ model. (b) 3D model. 
the discrete element bond model at different temperatures were determined.

(iv) Comparing the DEM simulation results and the lab test results of the splitting test illustrated that the three-dimensional parallel bond model is more suitable for simulating the load-displacement behavior of asphalt mixture. However, the DEM models presented in this study are not accurate in simulating the brittle failure process of asphalt mixture at low temperature.

\section{Data Availability}

The data supporting the conclusions of the present study can be obtained from the corresponding author.

\section{Conflicts of Interest}

All the authors declare that there are no conflicts of interests regarding the publication of this article.

\section{Authors' Contributions}

Jingsong Shan and Yang Du conceived and designed the laboratory experiments, Dahai Fan and Laiyao Guo performed the laboratory experiments, Jingsong Shan conducted the theoretical analysis, and Du Yang analyzed the laboratory data and wrote the paper.

\section{Acknowledgments}

This research was funded by a project of Shandong Province Higher Educational Science and Technology Program under grant number J17KA213.

\section{References}

[1] J. Pei, J. Zhang, and M. Chang, "Influence of mineral aggregate gradation on air void distribution characteristic of porous asphalt mixture," China Journal of Highway and Transport, vol. 23, no. 1, pp. 1-6, 2010.

[2] X. Huang, H. Li, and Y. Zhang, "Micromechanics analysis of viscoelasticity for asphalt mixtures considering influences of coarse aggregates and voids," Journal of South China University of Technology (Natural Science Edition), vol. 37, no. 7, pp. 31-36, 2010.

[3] J. Zhang, J. Peng, J. Zheng, L. Dai, and Y. Yao, "Prediction of resilient modulus of compacted cohesive soils in south China," International Journal of Geomechanics, vol. 19, no. 7, article 04019068, 2019.

[4] J. Li, J. Zhang, G. Qian, J. Zheng, and Y. Zhang, "Threedimensional simulation of aggregate and asphalt mixture using parameterized shape and size gradation," Journal of Materials in Civil Engineering, vol. 31, no. 3, article 04019004, 2019.

[5] F. Gu, W. Ma, R. C. West, A. J. Taylor, and Y. Zhang, "Structural performance and sustainability assessment of cold central-plant and in-place recycled asphalt pavements: a case study," Journal of Cleaner Production, vol. 208, pp. 1513-1523, 2019.
[6] L. Rothenburg and R. J. Bathurst, "Micromechanical features of granular assemblies with planar elliptical particles," Géotechnique, vol. 42, no. 1, pp. 79-95, 1992.

[7] W. G. Buttlar and Z. You, "Discrete element modeling of asphalt concrete: a micro-fabric approach," Transportation Research Record: Journal of the Transportation Research Board, vol. 1757, no. 1, pp. 111-118, 2001.

[8] Z. You and W. G. Buttlar, "Micromechanical modeling approach to predict compressive dynamic moduli of asphalt mixture using the distinct element method," Transportation Research Record: Journal of the Transportation Research Board, vol. 1970, no. 1, pp. 72-83, 2006.

[9] G. Dondi, A. Simone, V. Vignali, and G. Manganelli, "Numerical and experimental study of granular mixes for asphalts," Powder Technology, vol. 232, pp. 31-40, 2012.

[10] G. Dondi, S. Andrea, and V. Valeria, "Discrete particle element analysis of aggregate interaction in granular mixes for asphalt," in Proceedings of the 7th RILEM International Conference on Cracking in Pavements, A. Scarpas, N. Kringos, and I. A. Qadi, Eds., pp. 389-398, Springer, Delft, The Netherlands, June 2012.

[11] Z. Hossain, B. Indraratna, F. Darve, and P. K. Thakur, "DEM analysis of angular ballast breakage under cyclic loading," Geomechanics and Geoengineering, vol. 2, no. 3, pp. 175-181, 2007.

[12] H. Yu and S. Shen, "Impact of aggregate packing on dynamic modulus of hot mix asphalt mixtures using three-dimensional discrete element method," Construction and Building Materials, vol. 26, no. 1, pp. 302-309, 2012.

[13] S. Shen and H. Yu, "Analysis of aggregate gradation and packing for easy estimation of hot-mix-asphalt voids in mineral aggregate," Journal of Materials in Civil Engineering, vol. 23, no. 5, pp. 664-672, 2011.

[14] S. Shen and H. Yu, "Characterize packing of aggregate particles for paving materials: particle size impact," Construction and Building Material, vol. 25, no. 3, pp. 13621368, 2011.

[15] X. Yang, Z. You, C. Jin, A. Diab, and M. R. M. Hasan, "Aggregate morphology and internal structure for asphalt concrete: prestep of computer-generated microstructural models," International Journal of Geomechanics, vol. 18, no. 10, article 06018024, 2018.

[16] X. Yang, Q. Dai, Z. You, and Z. Wang, "Integrated experimental-numerical approach for estimating asphalt mixture induction healing level through discrete element modeling of a single-edge notched beam test," Journal of Materials in Civil Engineering, vol. 27, no. 9, article 04014259, 2014.

[17] X. Yang, S. Chen, and Z. You, “3D voxel-based approach to quantify aggregate angularity and surface texture," Journal of Materials in Civil Engineering, vol. 29, no. 7, article 04017031, 2017.

[18] X. Yang, Z. You, and J. Hu, “Three-dimensional finite-element modeling for asphalt concrete using visual cross-sectional imaging and indirect element meshing based on discreteelement models," Journal of Materials in Civil Engineering, vol. 29, no. 1, article 04016182, 2017.

[19] H. Kim and W. G. Buttlar, "Discrete fracture modeling of asphalt concrete," International Journal of Solids and Structures, vol. 46, no. 13, pp. 2593-2604, 2009.

[20] C. Jun and H. Xiaoming, "Simulation of fracture process of asphalt mixture using three-dimension discrete element method," Journal of South China University of Technology (Natural Science Edition), vol. 40, no. 7, pp. 21-26, 2012. 
[21] H. Zelelew, Simulation of the Permanent Deformation of Asphalt Concrete Mixtures Using Discrete Element Method, Washington State University, Pullman, WA, USA, 2008.

[22] H. M. Zelelew and A. T. Papagiannakis, "Micromechanical modeling of asphalt concrete uniaxial creep using the discrete element method," Road Materials and Pavement Design, vol. 11, no. 3, pp. 613-632, 2010.

[23] H. Zelelew, M. Enad, and A. T. Papagiannakis, "Micromechanical simulation of the permanent deformation properties of asphalt concrete mixtures," in Multi-Scale Modeling and Characterization of Infrastructure Materials, N. Kringos, B. Birgisson, and D. Frost, Eds., pp. 421-432, Springer, Berlin, Germany, 2013.

[24] C. Jun and H. Xiaoming, "Numerical analysis on multi-scale structure of asphalt concrete pavement," Journal of Building Materials, vol. 15, no. 2, pp. 116-121, 2012.

[25] W. Duanyi and Z. Xi, "Simulation of uniaxial compression test for asphalt mixture with discrete element method," Journal of South China University of Technology (Natural Science Edition), vol. 37, no. 7, pp. 37-41, 2009.

[26] L. Fan, Simulation of Influence of Aggregate Homogeneity on Mechanical Properties in Asphalt Mixtures Based on Discrete Element Method, ZheJiang University, Hangzhou, China, 2014.

[27] F. Sheng, L. Hou, Y. Wang, Z. Li, and J. Shan, "Studying on the parameters of bond model in DEM for Asphalt mixture," IOP Conference Series: Materials Science and Engineering, vol. 392, article 022004, 2018. 


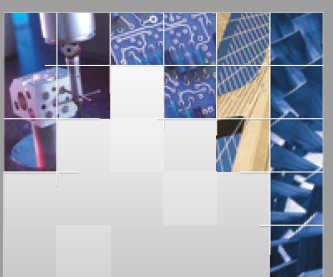

\section{Enfincering}
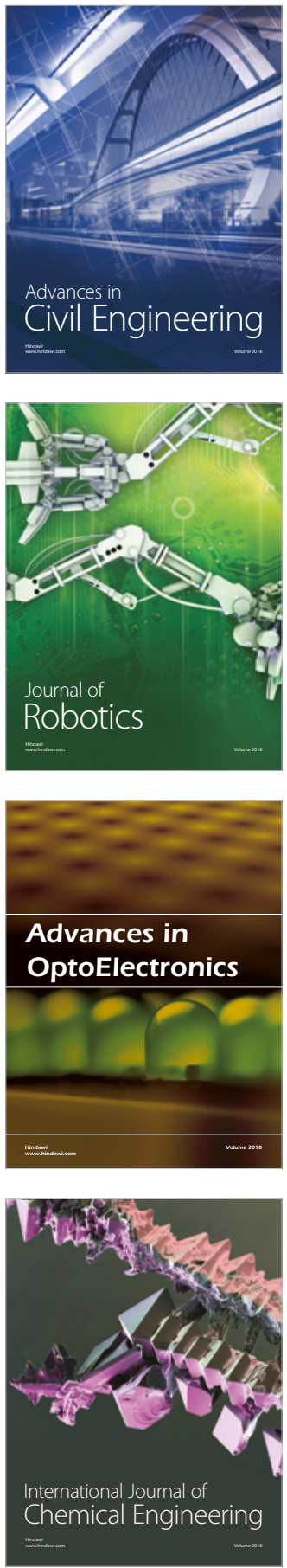

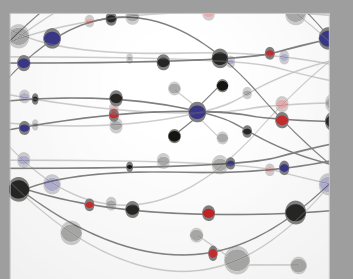

\section{Rotating \\ Machinery}

The Scientific World Journal

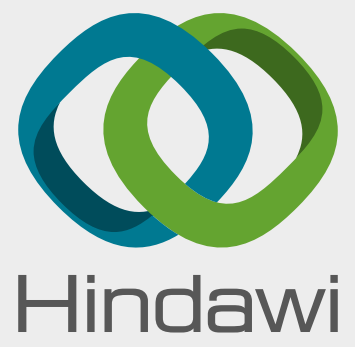

Submit your manuscripts at

www.hindawi.com
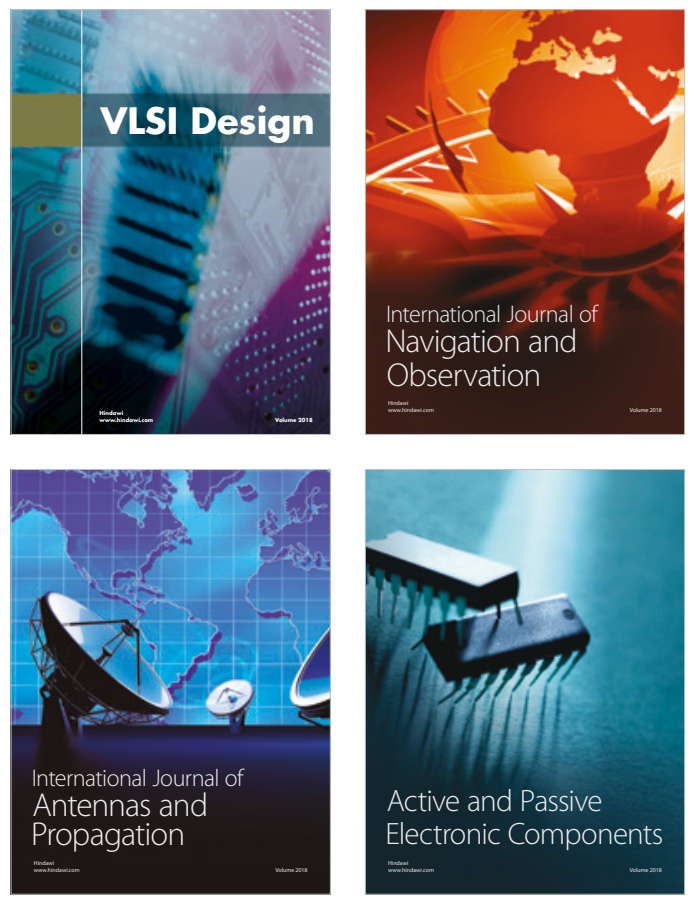
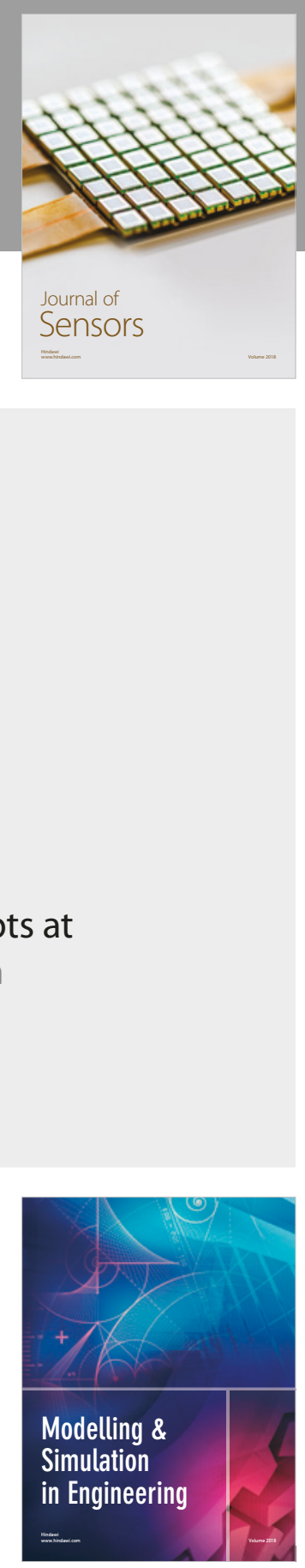

\section{Advances \\ Multimedia}
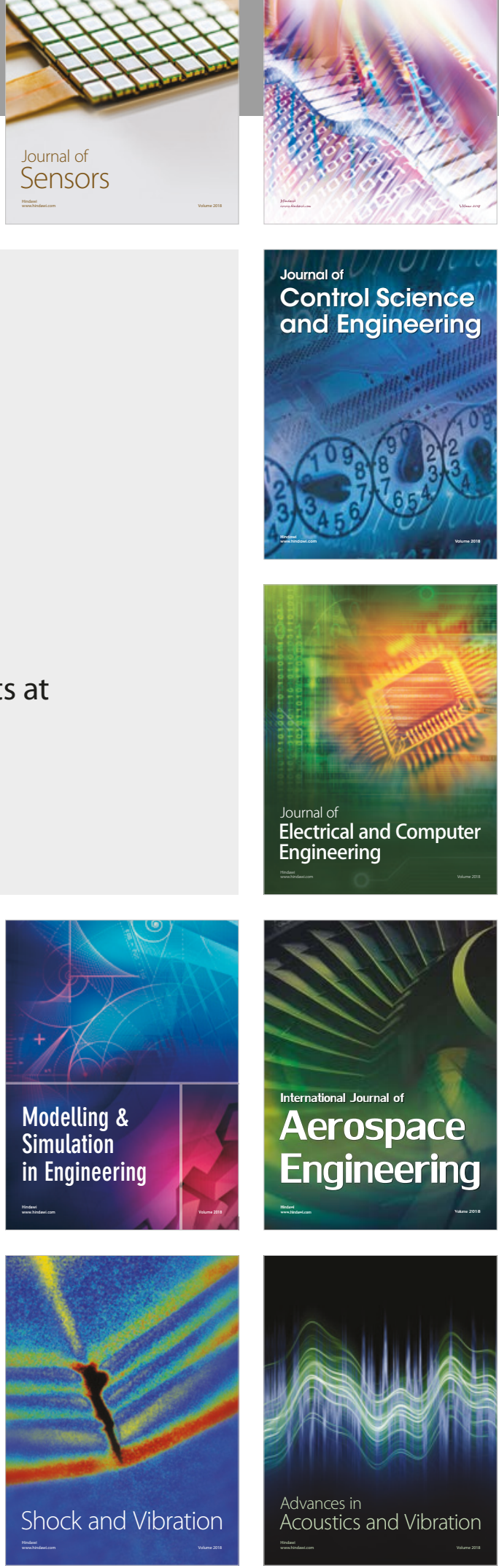